\title{
PFC Control for LED Lamp Driver Using Sensorless Predictive Current Controller
}

\author{
Mohamed S. Zaky \\ Department of Electrical Engineering \\ Northern Border University \\ Arar, Saudi Arabia \\ mszaky78@yahoo.com
}

\author{
Haitham Z. Azazi \\ Faculty of Electrical Engineering \\ Menoufia University \\ Shebin El-Kom, Egypt \\ haitham_azazi@yahoo.com
}

\author{
Ezzeddine Touti \\ Department of Electrical Engineering \\ Tunis University \\ Montfleury, Tunisia \\ touti.these09@gmail.com
}

\begin{abstract}
Light-emitting diodes (LEDs) have recently become of utmost significance to replace conventional lighting sources. Power factor correction (PFC) control of LED lamps requires three sensors which cause more cost, increase time delay, and increase noise, thus reducing drive reliability. Alternative methods to estimate the inductor current instead of its measurement are mandatory. This paper proposes a sensorless predictive current controller to enhance power factor (PF) of LED lamp driver and reduce driver cost. The inductor current is estimated instead of employing current sensor relying on measured input and output voltages. Zero-crossing detector is utilized to accomplish robust performance during distorted supply voltage. The controller and power circuit are isolated. The control algorithm employs a two-loop control to achieve a high PF with sinusoidal input current. Rapid speed performance is accomplished. The influences of $\mathrm{PFC}$ on input current value, $\mathrm{PF}$ and harmonic orders are presented. A prototype LED lamp driver with the suggested PFC structure is tested practically by a digital signal processor (DSP) DS1104 platform to validate its effectiveness. Experimental tests under various working conditions are provided to prove the usefulness of the suggested PFC control.
\end{abstract}

Keywords-LED lamp; power factor correction; sensorless control; predictive control; $D C / D C$ converter

\section{INTRODUCTION}

Twenty percent of worldwide consumed power is spent on lighting. To decrease the price of the consumed lighting power, light-emitting diode (LED) lamps were deployed. They have various advantages over conventional light sources, like long lifetime, high resistance to mechanical vibrations, high reliability, higher optical efficiency, uncomplicated interface circuit, smaller size, and they are mercury-free [1-3]. AC/DC converters are wanted to energize LED lamps [4]. Traditional AC/DC rectifier circuit using filter capacitor was used in [5]. Filter capacitor minimizes considerably the ripples of the output voltage [6]. However, it causes ripples in the supply current. Moreover, it draws discontinuous current from utility [6]. This creates some difficulties such as decrease of available power and increase of losses [7]. Power factor correction (PFC) circuits are commonly utilized to give sinusoidal input current [8]. PFC circuit must achieve the needs of international harmonic standards. AC/DC LED drivers for lighting with power larger than $25 \mathrm{~W}$ must fulfil current harmonic borders, IEC61000-3-2 class C [9]. Single-stage PFCs were considered the best converters regarding lighting purposes. In [10], PFC and regulator structures were combined together. These guarantee ease circuit control, minimized size, a close to unity power factor (PF), and increased efficiency [11]. Numerous methods to enhance PF and current distortions for LED lamps were employed in [12-14]. The majority of these approaches were depending on traditional analog control principles. They fundamentally carry out analog control principles in a digital form [15]. In traditional digital execution, division and multiplication processes can be realized via software. As all computations are performed in each switching period, so, implementation of traditional approaches needs rapid digital controllers. While various discrete PFC techniques were offered in $[16,17]$, many issues of digital applications like high computation burden, augmented price, and restricted switching frequency in comparison to analog control needed to be remedied. To attain large switching frequency with the required specifications, a predictive digital PFC scheme was employed in [16]. It achieves minimized cost, small computation burden, and improved behaviour compared with the traditional PFC approaches.

PFC control of LEDs, requires three kinds of sensors for detecting input current, inductor current and output voltage. Current sensors are commonly utilized in order to capture inductor current. But, using sensors with interface circuits costs more, increases time delay, and increases noise. This reduces the drive reliability. The input current sensing is considered a significant issue. A resistive sensor is generally utilized in practice. Nevertheless, it introduces extra cost, power loss, and heating. So, sensorless current control PFC schemes were employed. In $[16,18]$, the current was predicted for improving the power section behavior. PFC algorithms using digital current reconstruction suffer from difficult mathematical computation [19]. Also, the supply current may be distorted and there is a phase difference in the input voltage. In [20], PFC-based on Kalman filters for current sensorless controller was presented. However, it has large computation modeling and the input current has some distortion. In [21, 22], control approach using current law was introduced, in which, the instantaneous input current and proportional gain was applied 
to manage a constant DC link voltage. But, this approach neglects current compensation. For these issues, alternative methods to estimate the inductor current instead of its measurement are mandatory. Thus, sensorless current techniques are considered a suitable solution in terms of cost and reliability. Moreover, stable performance during transition state besides protecting instruments against over current is considered a big challenge.

This paper suggests a sensorless predictive current controller to improve the PF of LED lamp driver and reduce cost. Inductor current is estimated. The power circuit and the controller using the proposed scheme are isolated. The control structure is relied on a two-loop control to attain a high PF with sinusoidal input current. Rapid speed performance is also accomplished. The impact of PFC on the input current is presented. Theoretical analysis, simulation modeling, and experimental verifications of LED lamp driver with the proposed PFC control are presented.

\section{LED LAMP DRIVER}

\section{A. System Structure}

The structure of the LED lamp driver with its proposed sensorless predictive current controller is demonstrated in Figure 1. The system is consists of a LED lamp string fed from a DC-DC boost converter. The boost converter is fed from single-phase full bridge rectifier and step-down transformer. The proposed sensorless PFC control consists of two control circuits. A proportional-integral (PI) controller in the external circuit is employed for the voltage control to adjust the LED lamp output voltage $\left(V_{o}\right)$. Reference and actual voltages are compared and the difference is fulfilled with the PI voltage controller. The resultant output is considered the scaling factor of the rectified voltage $V_{\text {in }}$. The reference current $i_{\text {Lref }}$ can be obtained by multiplying this scaling factor with $V_{\text {in }}$ and dividing by the square of the root mean square (RMS) of $V_{i n}$. The second control circuit can be considered the current controller. This circuit is structured with the inductor current $\hat{i_{L}}$ and a predictive current controller. The current estimation module is using rectified voltage and output voltage to estimate the inductor current.

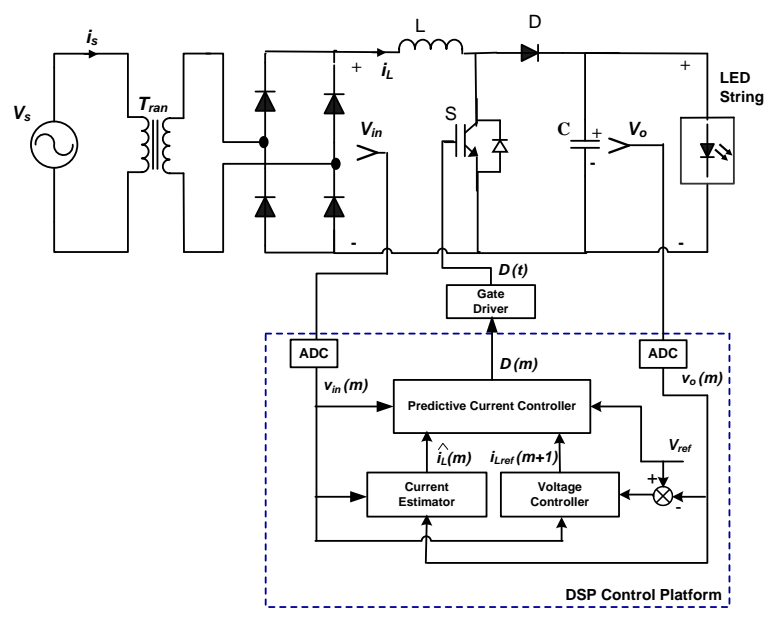

Fig. 1. LED driver topology and proposed control

\section{B. Modeling of LEDs}

To appropriately design the proposed PFC converter, modeling of the load of the LED is needed. A comparison between I-V characteristics of LED load and resistive load is displayed in Figure 2. The resistance of each load can be obtained by the inverse of each curve slope. The dynamic resistance of the LED load is much lesser than the corresponding resistive load. As obvious, the LED characteristics cause instability problems.

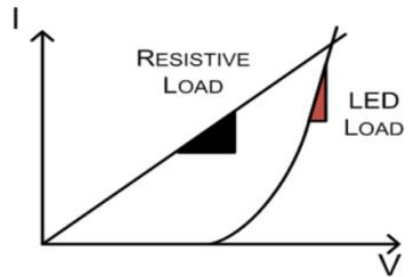

Fig. 2. Comparisons of I-V characteristics of LED and resistive loads.

The I-V relationship of LED shown in Figure 2 is given by:

$$
I=a e^{b V}
$$

where, $a$ and $b$ are separate gains. The correlation in (1) shows the minimum dynamic resistance of LED at operating condition. This is a simple model that considers only the device equivalent resistance during normal working point. But, this assumption causes undesirable errors. These errors result from the large variation of the equivalent and dynamic resistances at the working point. The actual dynamic resistance is much smaller than the equivalent resistance. Thus, the most common approximation model is the one containing a threshold voltage connected in series with a dynamic resistance, as seen in Figure 3 [23].

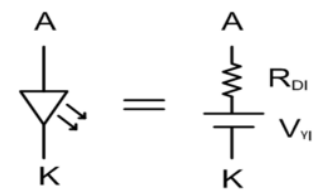

Fig. 3. Approximate equivalent circuits of LED string.

Therefore, the I-V model of the LED load can be as:

$$
V_{D}=R_{d i} I_{d}+V_{\gamma i}
$$

where $V_{D}$ is the forward voltage drop on one LED, $R_{d i}$ the dynamic resistance, $I_{d}$ the LED forward current, and $V_{\gamma i}$ the threshold voltage. The relationship of the output voltage for a complete string in series is described by the product of (2) with the number of LEDs connected in series:

$$
V_{o}=N\left(R_{d i} I_{d}+V_{\gamma i}\right)=R_{D I} I_{D}+V_{\gamma I}
$$

where, $V_{o}$ is the LED string output voltage and $N$ the number of LEDs connected in series.

LED model can be attained via capturing the voltage $V_{o}$ and forward current $I_{D}$ in the laboratory to get the dynamic resistance and load threshold voltage. The rated power demand for most LED street lights ranges from $60 \mathrm{~W}$ to $150 \mathrm{~W}$. The 
LED lamp selected in this paper consists of three branches in parallel. Each branch consists of 19 LEDs. Each LED current is $350 \mathrm{~mA}$. This provides a total of 60 LEDs consuming $60 \mathrm{~W}$ at string output voltage $60 \mathrm{~V}$. The LED threshold voltage and dynamic resistance are $2.8 \mathrm{~V}$ and $1.03 \Omega$.

\section{DESIGN OF PREDICTIVE CURRENT CONTROLLER}

The predictive current controller for LED lamp driver working in continuous conduction mode (CCM) as demonstrated in Figure 1 is presented in this section. Some assumptions for analysis simplification are:

- The switch $\mathrm{S}$ and diode D can be considered ideal.

- The input voltage $V_{\text {in(t) }}$ is a full-wave rectified, i.e., $v_{i n}(t)=V_{m}\left|\sin \left(\omega_{e} t\right)\right|$, where $V_{m}$ is the peak value of $\mathrm{AC}$ supply voltage and $\omega_{e}=2 \pi f$ is the angular frequency.

- The capacitor $\mathrm{C}$ is large enough to ignore the frequency voltage ripple.

- $\quad$ The switching frequency should be greater than the supply frequency. Thus, input and output voltages of the boost converter are assumed as constant through one switching period $\mathrm{T}$.

The suggested LED driver has two modes of operation during a switching cycle. Figure 4 illustrates these two operation modes.

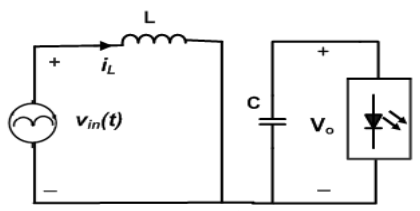

(a) Mode 1

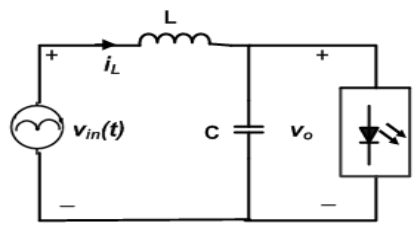

(b) Mode 2

Fig. 4. Two equivalent circuits of the boost LED driver working in CCM

1) Mode 1: $m \leq t<m+d_{r}(m) T_{s}$

Referred to Figure 1, when the switch $S$ is on. Accordingly, the inductor voltage is $v_{i n}(t)$. Therefore, $i_{L}(t)$ is obtained from:

$$
v_{i n}(t)=L \frac{d i_{L}(t)}{d t}
$$

where $L$ is the coil inductance.

2) Mode 2: $m+d_{r}(m) T_{s} \leq t<m+1$

The switch $\mathrm{S}$ is off. Therefore, $i_{L}(t)$ decreases linearly as:

$$
v_{\text {in }}(t)-v_{o}(t)=L \frac{d i_{L}(t)}{d t}
$$

The equations of mode 1 and mode 2 can be arranged as (6) and (7) because the switching frequency is much higher than the supply frequency.

$$
\begin{aligned}
& v_{i n}(m)=L \frac{i_{L}\left(m+d_{r}(m) T_{s}\right)-i_{L}(m)}{d_{r}(m) T_{s}} \\
& v_{\text {in }}(m)-v_{o}(m)=L \frac{i_{L}(m+1)-i_{L}\left(m+d_{r}(m) T_{s}\right)}{1-d_{r}(m) T_{s}}
\end{aligned}
$$

Where, $m$ and $(m+1)$ are the starting moments of $m^{\text {th }}$ and $(m+1)^{\text {th }}$ switching periods, and $d_{r}(m)$ is the duty ratio in the $m^{\text {th }}$ switching period. $i_{L}(m)$ and $i_{L}(m+1)$ are the values of $i_{L}(t)$ at the starting of $m^{\text {th }}$ and $(m+1)^{\text {th }}$ switching periods. Figure 5 shows $i_{L}(t)$ at one switching period.

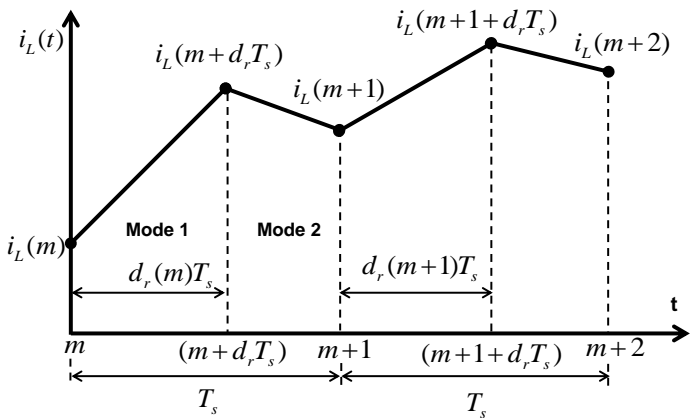

Fig. 5. Inductor current waveform in one switching period under predictive current control.

Equation (6) is used to derive $i_{L}(t)$ at the moment of switching off, $m+d_{r}(m) T_{s}$, by:

$i_{L}\left(m+d_{r}(m) T_{s}\right)=i_{L}(m)+\frac{d_{r}(m) T_{s}}{L} v_{i n}(m)$ in (9):

$i_{L}(t)$ during the starting moment at $(m+1)$ using $(7)$ is given

$$
\left.i_{L}(m+1)=i_{L}\left(m+d_{r}(m) T_{s}\right)\right)+\left(v_{i n}(m)-v_{o}(m)\right) \frac{\left[\left(1-d_{r}(m)\right) T_{s}\right]}{L}
$$

Using (8) and (9), $i_{L}(t)$ at the $(m+1)^{\text {th }}$ instant using $i_{L}(t)$ at the $m^{\text {th }}$ moment, is obtained by:

$$
i_{L}(m+1)=i_{L}(m)+\frac{v_{i n}(m)-v_{o}(m)\left[1-d_{r}(m) T_{s}\right]}{L}
$$

Transforming (10) to a digital structure gives:

$$
i_{L}(K+1)=i_{L}(K)+\frac{v_{i n}(K)-v_{o}(K)\left[1-d_{r}(K) T_{s}\right]}{L}
$$

It is observed that the inductor current in the next switching period $i_{L}(K+1)$ is calculated by the inductor current $i_{L}(K)$, the output and input voltages and the present duty ratio. The duty ratio is obtained from (11) as:

$$
d_{r}(K)=\frac{L}{T_{s}}\left[\frac{i_{L}(K+1)-i_{L}(K)}{v_{o}(K)}\right]+\frac{v_{o}(K)-v_{i n}(K)}{v_{o}(K) T_{s}}
$$

Equation (12) indicates that the desired duty ratio $d_{r}(K)$ for the present switching cycle is derived depending on the boost 
inductance, $i_{L}, v_{i n}$, and $v_{o}$.

For properly PFC design for the LED driver, the current controller forces $i_{L}(K+1)$ to track $i_{\text {ref }}(K+1)$. Also, the voltage controller forces $v_{o}(K)$ to track $V_{r e f}$. Alternatively, actual $i_{L}(K)$ is replaced with the estimated value $\hat{i}_{L}(K)$. Hence, the duty ratio is written by using (13):

$$
d_{r}(K)=\frac{L}{T_{s}}\left[\frac{i_{r e f}(K+1)-\hat{i_{L}}(K)}{V_{r e f}}\right]+\frac{V_{r e f}-v_{i n}(K)}{V_{r e f} T_{s}}
$$

The reference current is calculated by integrating the difference between $v_{o}(m)$ and $V_{\text {ref. }}$. Then, this integration output is multiplied by a generated absolute sine wave of unity amplitude. This sine wave can be completely synchronized with $V_{\text {in }}$ using the zero-crossing detection concept. The zerocrossing detector can be employed in the suggested scheme to attain high performance during distorted supply voltage. The inductor reference current $i_{r e f}(m+1)$ is obtained from Figure 6 as:

$$
i_{r e f}(m+1)=\left(K_{p} e(t)+K_{I}(t) \int e(t) d t\right)\left|\sin \left(\omega_{s} t(m+1)\right)\right|
$$

where $e(t)$ is the voltage error, $K_{P}$ is the proportional gain, and $K_{I}$ is the integral gain.

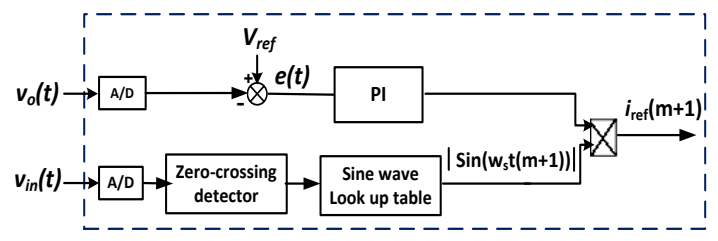

Fig. 6. Inductor reference current estimator.

\section{CURRENT ESTIMATE METHOD}

The proposed method of PFC control is employed without employing the current sensor to attain a close to unity PF of a LED lamp driver fed from a single-phase rectifier. The inductor current is estimated instead of the current sensor relied on the measured input and output voltages. The inductor current can be estimated from the two states of boost converter as follow:

- The rebuilt $\hat{i}_{l}(k)$ in On-state is introduced by:

$$
\hat{i}_{l}=\int \frac{v_{i n}(t)}{L} d t
$$

- The rebuilt $\hat{i}_{l}(k)$ in Off-state is expressed by:

$$
\hat{i}_{l}=\int \frac{v_{i n}(t)-v_{i}(t)}{L} d t
$$

The above two integration processes are bilaterally incorporated to estimate the inductor current $\hat{i}_{l}(t)$. Figure 7 displays the block diagram of the inductor current estimator for PFC of LED driver to attain PF close to unity. The inductor current is computed using the actual output and input voltages.
Estimated and reference currents are considered the inputs of the predictive current controller. Then, the output is used as a feedback to control the command signal's on and off state. Furthermore, it is used as an input to the pulse with modulator (PWM) for controlling the boost converter switch states.

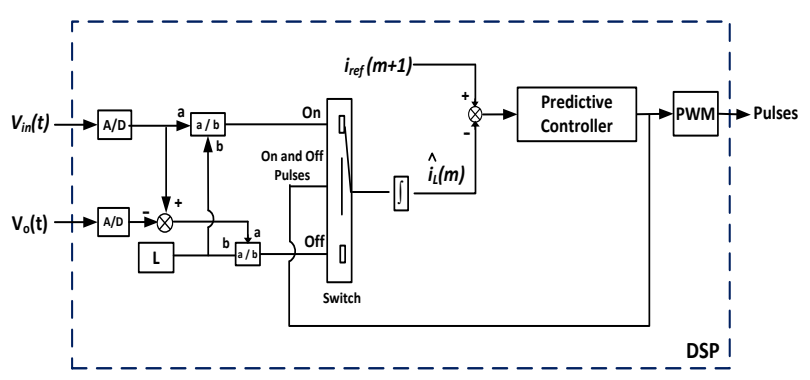

Fig. 7. Inductor current estimator

\section{RESULTS AND DISCUSSION}

\section{A. Laboratory System Setup}

To examine the performance of the LED system, a laboratory implementation of the LED system is carried out using the proposed controller approach. Figure 8 shows a photo of the real-time experimental system using DSP-DS1104 control platform. The experimental system consists of $60 \mathrm{~W}$ LED streetlight, DC-DC boost converter, single-phase auto transformer, gate drive and interface circuits, voltage sensors, and a DS11104 control board.

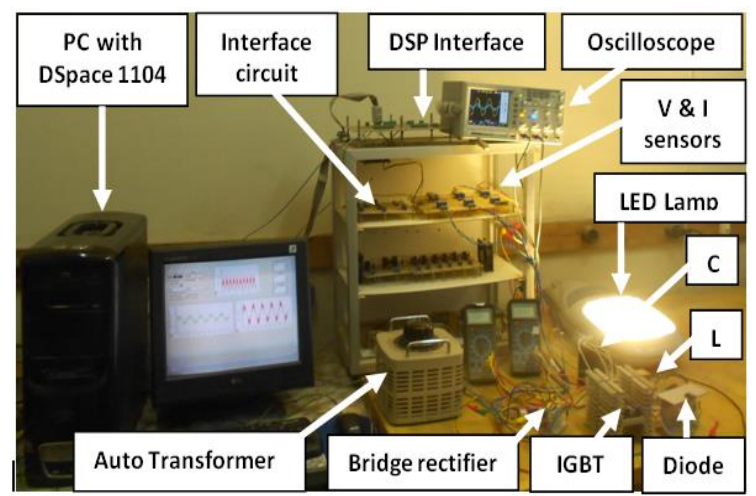

Fig. 8. Photo of the real-time experimental system of the LED system using DSP-DS1104 control platform.

The experiment is implemented with a grid phase voltage of $220 \mathrm{~V}$, and the LED lamp is fed from the boost converter, which is consisting of coil, fast recovery diode (DESI 60), single power switch (IGBTs) and a gate interface board. The IGBT used in the experimental system is MITSUBISHI IGBT Module (CM50DY-24H) 50A/1200V. The LED lamp consists of three branches in parallel. Each branch has 19 LEDs. Single LED current is $350 \mathrm{~mA}$. The input voltage and output voltage are measured using voltage sensors (LV25-P) and sent to the dSPACE-DS1104 control board via the A/D converter port. The DSP platform uses a dSPACE-DS1104. MATLAB/Simulink software is employed for model built. The dSPACE board has facilitated to capture the experimental 
waveforms and exports them numerically per sample. Table I provides the main converter specifications used for the experimental system.

TABLE I. SYSTEM PARAMETERS

\begin{tabular}{|c|c|}
\hline Parameters & Values \\
\hline $\boldsymbol{V}_{\boldsymbol{s}}(\boldsymbol{R M} \boldsymbol{M})$ & $220 \mathrm{~V}$ \\
\hline $\boldsymbol{f}$ & $50 \mathrm{~Hz}$ \\
\hline $\boldsymbol{V}_{\boldsymbol{o}}(\boldsymbol{A} \boldsymbol{V G})$ & $60 \mathrm{~V}$ \\
\hline $\boldsymbol{I}_{\boldsymbol{o}}(\boldsymbol{A} \boldsymbol{V G})$ & $1 \mathrm{~A}$ \\
\hline $\boldsymbol{P}_{\boldsymbol{L E D}}$ & $60 \mathrm{~W}$ \\
\hline $\boldsymbol{L}$ & $2 \mathrm{mH}$ \\
\hline $\boldsymbol{C}$ & $1000 \mu \mathrm{F}$ \\
\hline $\boldsymbol{T r}$ & $220: 24 \mathrm{~V} \mathrm{rms}$ \\
\hline
\end{tabular}

\section{B. Results}

Figure 9 shows the steady state simulation and experimental tests of supply voltage and current waveforms for LED lamp driver. This figure implies that the supply current $i_{s}$ and the supply voltage $V_{s}$ are sinusoidal and in phase. Figure 10 displays the harmonics spectrum of $i_{s}$ (up to $20^{\text {th }}$ ) in simulation and experimental tests. As noted, THD of the supply current using the suggested LED driver is $3 \%$ and the PF is 0.9996. This meets IEC-61000-3-2 class C limit with large margins.

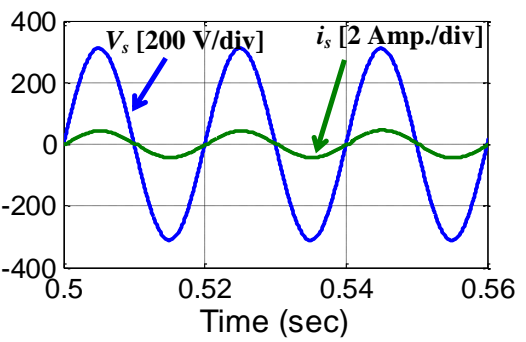

(a) Simulation

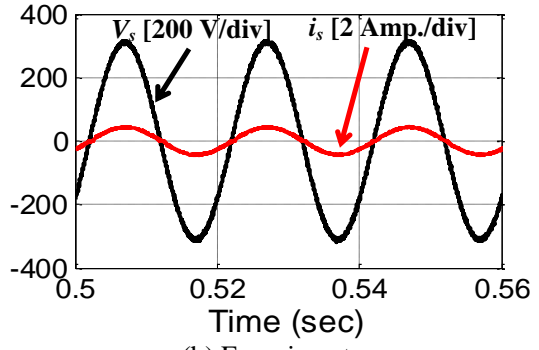

(b) Experiment

Fig. 9. Steady-state tests showing the supply voltage and current.

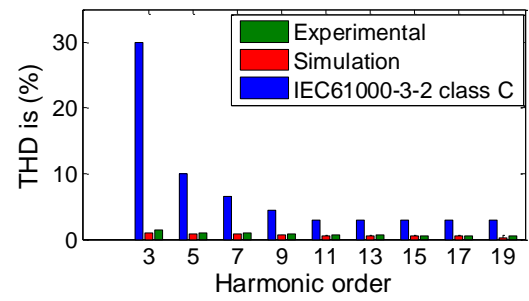

Fig. 10. Harmonics spectrum of supply current.
Steady-state results showing the actual current and estimated coil current are displayed in Figure 11. As obvious, the estimated coil current is precise enough, permitting the inductor current immediately tracks the reference current variation and achieve the required response. Figure 12 displays the LED voltage and current at steady-state.

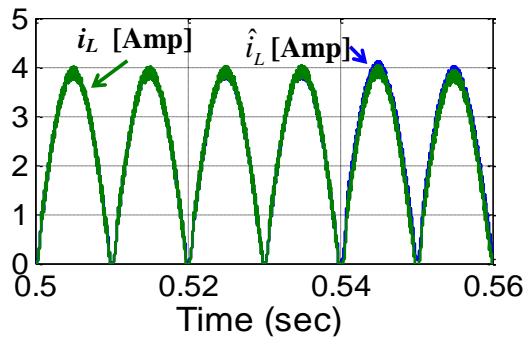

(a) Simulation

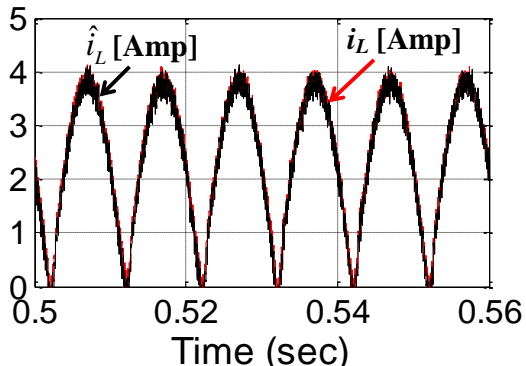

(b) Experiment

Fig. 11. Steady-state results showing the actual current and estimated coil current.

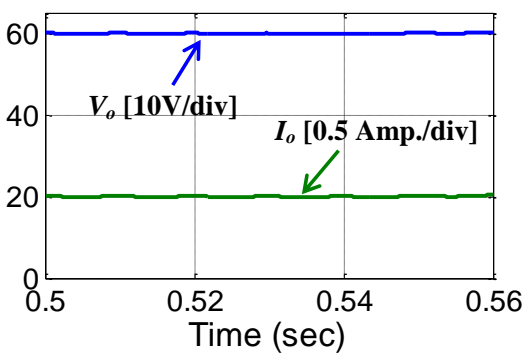

(a) Simulation

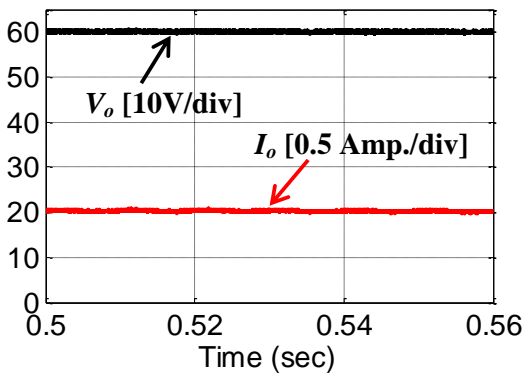

(b) Experiment

Fig. 12. Steady-state results LED voltage and current

Voltage and current of the LED driver are DC nearly without ripples. Figures 13-15 demonstrate the waveforms of supply voltage and current under various voltage levels. These 
figures prove that the supply current $i_{s}$ and the supply voltage $V_{s}$ are sinusoidal and in phase.

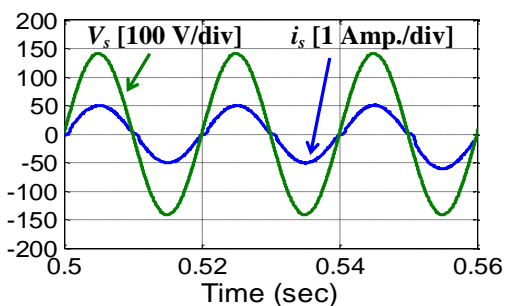

(a) Simulation

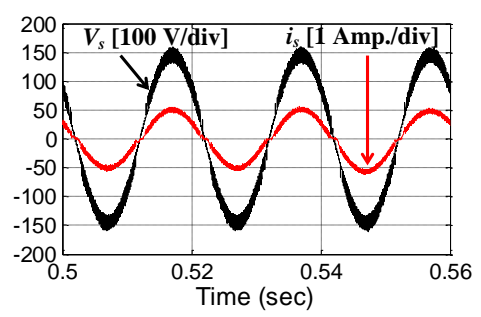

(b) Experiment

Fig. 13. Supply voltage and current at $100 \mathrm{~V}$ rms.

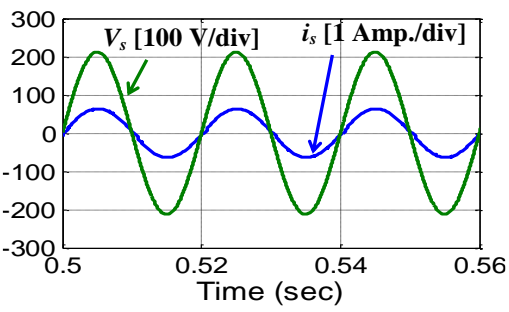

(a) Simulation

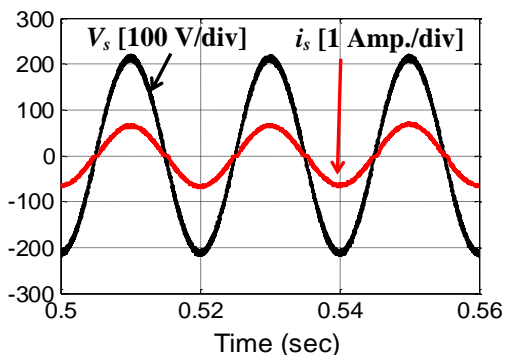

(b) Experiment

Fig. 14. Supply voltage and current at $150 \mathrm{~V}$ rms.

The robustness of the proposed control technique is checked at step changes in the reference voltage as displayed in Figure 16. It is evident that the proposed converter achieves a fast recovery time to its reference voltage.

Figure 17 demonstrates transient response of supply voltage variations. The transient response of output voltage and current during supply voltage changes is displayed in Figure 18. As noted, the output voltage can be attainted at its reference value under the changes in supply voltage and the system has a good dynamic response against sudden variations of the source voltage.

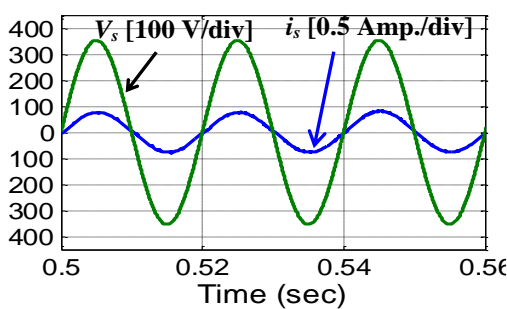

(a) Simulation

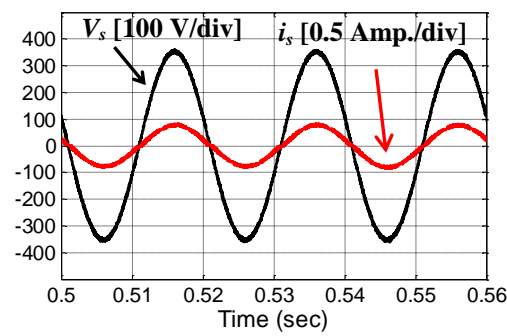

(b) Experiment

Fig. 15. Supply voltage and current at $250 \mathrm{~V}$ rms

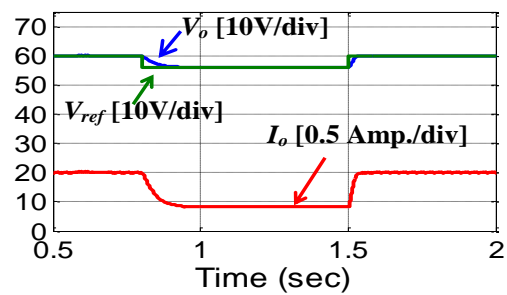

(a) Simulation

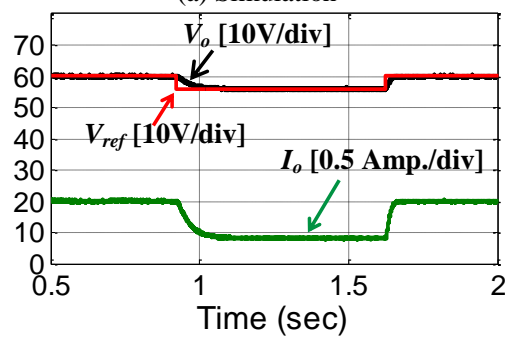

(b) Experiment

Fig. 16. Transient response due to reference voltage changes

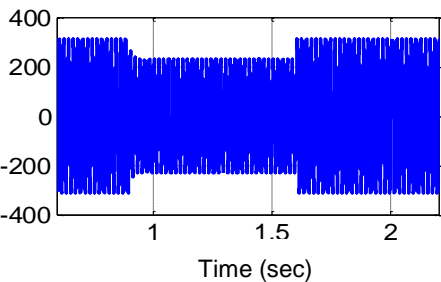

(a) Simulation

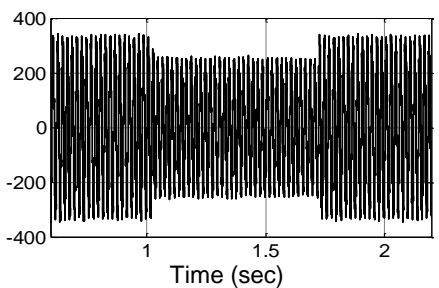

(b) Experiment

Fig. 17. Transient response showing supply voltage changes. 


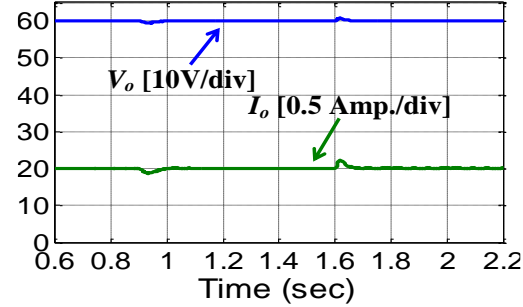

(a) Simulation

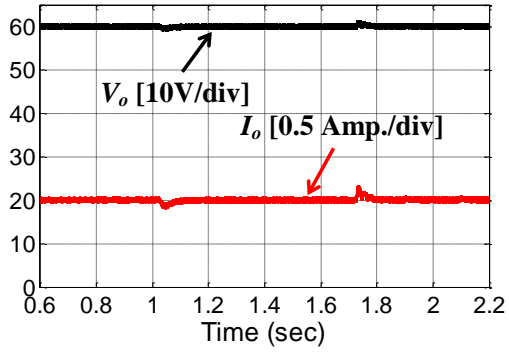

(b) Experimental

Fig. 18. Transient response showing output voltage and current due to supply voltage changes.

\section{CONCLUSION}

A sensorless predictive current controller for LED lamp driver was proposed. The sensorless current scheme was designed to estimate the inductor current relied on the sampled value of input and output voltages. This scheme achieves reliability and simplicity on estimating inductor current. This remedies the issues of a current sensor. The predictive current controller generates the duty cycles in advance relied on the reference and estimated inductor currents and input and output voltages. The proposed PFC control technique has low computation burden and it has been executed using a minimum cost digital signal processor to accomplish high switching frequency. Results demonstrated the advantages of the suggested driver with a high PF and sinusoidal supply current waveform with low harmonics, complying with IEC 61000-3-2 class C. The proposed scheme can attain good dynamic performance for reference and supply voltage changes.

\section{ACKNOWLEDGEMENT}

Authors acknowledge the approval and support of this research study by the grant no. ENG-2017-1-8-F-7217 from the Deanship of Scientific Research at Northern Border University, Arar, KSA.

\section{REFERENCES}

[1] E. F. Schubert, Light-Emitting Diodes, E. Fred Schubert, 2006

[2] A. Zukauskas, M. S. Shur, R. Gaska, Introduction to Solid-State Lighting, Wiley, pp. 79-82, 2002

[3] C. C. Wang, K. H. Wu, Y. C. Liu, C. Y. Yang, M. M. Alam, Y. K. Lo, H. J. Chiu, "Study and implementation of an improved power factor alternating-current-light emitting diode driver", IET Power Electronics, Vol. 8, No. 7, pp. 1156-1163, 2015

[4] C. Moo, Y. Chen, W. Yang, "An efficient driver for dimmable LED lighting", IEEE Transactions on Power Electronics, Vol. 27, No. 11, pp. 4613-4618, 2012

[5] J. C. Lam, P. K. Jain, "Isolated AC/DC Offline High Power Factor Single-switch LED Drivers without Electrolytic Capacitors", IEEE Journal of Emerging and Selected Topics in Power Electronics ,Vol. 3, No. 3, pp. 679-690, 2015
[6] S. W. Lee, H. L. Do, "A Single-Switch AC-DC LED Driver Based on a Boost-Flyback PFC Converter with Lossless Snubber”, IEEE Transactions on Power Electronics, Vol. 32, No. 2, pp. 1375-1384, 2017

[7] U. Anwar, D. Maksimovic, K. K. Afridi, "A simple control architecture for four-switch buck-boost converter based power factor correction rectifier", IEEE 18th Workshop on Control and Modeling for Power Electronics, Stanford, USA, July 9-12, 2017

[8] H. Wu, S. C. Wong, C. K. Tse, S. Y. Ron Hui, Q. Chen, "Single-Phase LED Drivers with Minimal Power Processing, Constant Output Current, Input Power Factor Correction, and without Electrolytic Capacitor", IEEE Transactions on Power Electronics, Vol. 33, No. 7, pp. 6159-6170, 2017

[9] Hewlett-Packard, Compliance Testing to the IEC 1000-3-2 (EN 610003-2) and IEC 1000-3-3 (EN 61000-3-3) Standards, Application Note 1273, Hewlett Packard Co., 1995

[10] C. Trujillo, G. Henao, J. Castro, A. Narvaez, "Design and development of a LED Driver prototype with a Single-Stage PFC and low current harmonic distortion", IEEE Latin America Transactions, Vol. 15, No. 8 , pp. 1368-1375, 2017

[11] D. C. Lu, "High Voltage Stress in Single-Phase Single-Stage PFC Converters: Analysis and an Alternative Solution", IEEE Transactions on Power Electronics, Vol. 63, No. 1, pp. 133-143, 2016

[12] H. L. Cheng, Y. N. Chang, C. A. Cheng, C. H. Chang, Y. H. Lin, "Highpower-factor dimmable LED driver with low-frequency pulse-width modulation", IET Power Electronics, Vol. 9, No. 10, pp. 2139-2146, 2016.

[13] J. B. Baek, S. Chae, "Single-Stage Buck-Derived LED Driver With Improved Efficiency and Power Factor Using Current Path Control Switches", IEEE Transactions on Industrial Electronics, Vol. 64, No. 10, pp. 7852-7861, 2017

[14] B. White, H. Wang,Y. F. Liu, X. Liu, "An Average Current Modulation Method for Single-Stage LED Drivers With High Power Factor and Zero Low-Frequency Current Ripple", IEEE Journal of Emerging and Selected Topics in Power Electronics, Vol. 3, No. 3, pp. 714-731, 2015

[15] W. Zhang, G. Feng, Y. F. Liu, B. Wu, "New digital control method for power factor correction", IEEE Transactions on Industrial Electronics, Vol. 53, No. 3, pp. 987-990, 2006

[16] J. Chen, A. Prodic, R. W. Erickson, D. Maksimovic, "Predictive digital current programmed control", IEEE Transactions on Power Electronics, Vol. 18, No. 1, pp. 411-419, 2003

[17] C. W. Clark, F. Musavi, W. Eberle, "Digital DCM Detection and Mixed Conduction Mode Control for Boost PFC Converters", IEEE Transactions on Power Electronics, Vol. 29, No. 1, pp. 347-355, 2016

[18] S. Bibian, H. Jin, "High performance predictive deadbeat controller for DC power supplies", IEEE Transactions on Power Electronics, Vol. 17, No. 3, pp. 420-427, 2002

[19] A. P. Finazzi, L. C. de Freitas, J. B. Vieira, E. A. A. Coelho, V. J. Farias, L. G. Freitas, "Current-sensorless PFC boost converter with preprogrammed control strategy", IEEE International Symposium on Industrial Electronics, Gdansk, Poland, June 27-30, 2011

[20] K. I. Hwu, H. W. Chen, Y. T. Yau, "Fully-digitalized implementation of PFC rectifier in CCM without ADC", 26th Annual IEEE Applied Power Electronics Conference and Exposition, Fort Worth, USA, March 6-11, 2011

[21] F. J. Azcondo, A. de Castro, V. M. Lopez, O. Garcia, "Power factor correction without current sensor based on digital current rebuilding", IEEE Transactions on Power Electronics, Vol. 25, No. 6, pp. 1527-1536, 2010

[22] J. W. Kimball, P. T. Krein, "A current-sensorless digital controller for active power factor correction control based on Kalman filters", 23rd Annual IEEE Applied Power Electronics Conference and Exposition, Austin, USA, February 24-28, 2008

[23] D. Gacio, J. M. Alonso, A. J. Calleja, J. Garcia, M. Rico-Secades, “A Universal-Input Single-Stage High-Power-Factor Power Supply for HBLEDs Based on Integrated Buck-Flyback Converter", 24th Annual IEEE Applied Power Electronics Conference and Exposition, Washington, DC, USA, February 15-19, 2009 